\title{
Patogénesis molecular, epidemiología y diagnóstico de Escherichia coli enteropatógena
}

\author{
Jorge E. Vidal, $\mathrm{PhD},{ }^{(1,2)}$ Adrián Canizález-Román, $\mathrm{PhD}{ }^{(3,4)}$ \\ Javier Gutiérrez-Jiménez, PhD, ${ }^{(5)}$ Fernando Navarro-García, PhD. ${ }^{\left({ }^{\prime}\right)}$
}

\author{
Vidal JE, Canizález-Román A, \\ Gutiérrez-Jiménez J, Navarro-García F. \\ Patogénesis molecular, epidemiología \\ y diagnóstico de Escherichia coli enteropatógena. \\ Salud Publica Mex 2007;49:376-386.
}

\section{Resumen}

Escherichia coli enteropatógena (EPEC) es una de las principales causas de diarrea en niños menores de dos años en países en vías de desarrollo. La principal característica histopatológica de la infección es una lesión que induce la EPEC en el intestino conocida como la lesión A/E (adherencia y eliminación). Las bacterias se adhieren a los enterocitos y permiten la acumulación de la actina del citoesqueleto en la región apical de la célula, hasta formar una estructura de tipo "pedestal" y causar la eliminación de las microvellosidades intestinales. A pesar de que se conoce de modo detallado el proceso de formación de los pedestales de actina, aún no se ha esclarecido el mecanismo global de la diarrea que induce EPEC. La diarrea se ha vinculado con:a) la destrucción de las microvellosidades del enterocito, b) la salida masiva de iones hacia la luz intestinal y c) la secreción de alguna enterotoxina. En estudios realizados en países en vías de desarrollo se ha demostrado que EPEC es uno de los principales agentes participantes en la diarrea infantil, con elevadas tasas de morbilidad y mortalidad. El diagnóstico microbiológico de la infección se realiza con metodologías adicionales a las utilizadas con regularidad en el laboratorio de microbiología clínica, entre ellas las siguientes:a) serotipificación, b) ensayo de adherencia, c) prueba de FAS (tinción fluorescente para actina) y d) detección específica de genes que codifican a proteínas incluidas en la patogénesis, como el bfpA y eae. Un objetivo de esta revisión es actualizar los avances observados en la patogénesis
Vidal JE, Canizález-Román A,

Gutiérrez-Jiménez J, Navarro-García F.

Molecular pathogenesis, epidemiology

and diagnosis of enteropathogenic Escherichia coli.

Salud Publica Mex 2007;49:376-386.

\section{Abstraet}

Enteropathogenic Escherichia coli (EPEC) is a leading cause of diarrhea in infants less than two years of age in developing countries. To induce diarrhea EPEC uses several virulence factors acting on a still unknown and mysterious mechanism. The hallmark of EPEC infection is a histological intestinal alteration known as the attaching and effacing (A/E) lesion.The bacterium attaches intimately to the enterocyte and induces assembly of cytoskeleton intracellular actin on the cellular surface. Rearrangements of the actin cytoskeleton form a pedestal-like structure where bacterium tightly cups the cells, leading to degeneration of brush border microvilli.Although the mechanism of EPEC-induced pedestal formation has been dissected in detail, the overall mechanism of diarrhea is still obscure. It is believed that EPEC-mediated secretory diarrhea is related to a) intestinal microvilli effacement, b) massive loss of intracellular ions into the intestinal milieu and c) secretion of an EPEC enterotoxin. Epidemiological studies conducted in developing countries have shown that EPEC is one of the main bacteria frequently isolated from children with diarrhea, causing high morbidity and mortality rates. The microbiological diagnosis of EPEC-induced disease is performed with analytic methodologies different from those used by the standard microbiology laboratory, the most relevant being: a) serotypification, b) the adherence assay, c) FAS test, and d) the specific detection of virulence-involved genes (bfpA and eae genes) using molecular biology techniques. The purpose of

(I) Departamento de Biología Celular, Centro de Investigación y Estudios Avanzados (Cinvestav). México, DF.

(2) Department of Molecular Genetics and Biochemistry, University of Pittsburgh, School of Medicine. Pittsburgh, PA, EUA.

(3) Laboratorio Estatal de Salud Pública de Sinaloa, Secretaría de Salud. Culiacán, Sinaloa, México.

(4) Facultad de Medicina, Universidad Autónoma de Sinaloa. Culiacán, Sinaloa, México.

(5) Laboratorio de Genética, Escuela de Biología, Universidad de Ciencias y Artes de Chiapas, Tuxtla Gutiérrez, Chiapas, México.

Fecha de recibido: 5 de septiembre de 2006 - Fecha de aceptado: 9 de julio de 2007

Solicitud de sobretiros: Dr. Jorge E.Vidal, 200 Lothrop st. Biomedical Science Tower WI I09,

Department of Molecular Genetics and Biochemistry, University of Pittsburgh, School of Medicine, Pittsburgh, PA, I526I, EUA.

Correo electrónico: jev20@pitt.edu 
molecular de la infección por EPEC, las metodologías para el diagnóstico microbiológico y la epidemiología en México y otros países en vías de desarrollo.

Palabras clave: Escherichia coli enteropatógena; diarrea infantil; virulencia; diagnóstico molecular; México this review is to update the most recent findings regarding the molecular pathogenesis of EPEC, its epidemiology in Mexico as well as other developing countries, and also the developed methodology for the diagnosis of EPEC infection.

Key words: Enteropathogenic E. coli; infantile diarrhea; virulence; molecular diagnosis; Mexico
E cherichia coli es el principal anaerobio facultativo de la flora microbiana que reside en el colon humano. El huésped se coloniza desde el nacimiento con una o dos cepas que residen de manera permanente en el intestino y establecen una relación simbiótica con el individuo durante toda la vida. ${ }^{1,2}$ Sin embargo, se ha precisado que seis grupos patógenos o patotipos de $E$. coli ocasionan diarrea en sujetos sanos: E. coli enterotoxigénica (ETEC), enteroinvasiva (EIEC), enterohemorrágica (EHEC), enteroagregativa (EAEC), adherente difusa (DAEC) y enteropatógena (EPEC). ${ }^{2}$

E. coli enteropatógena (EPEC, por sus siglas en inglés) fue la primera en describirse y es tal vez uno de los microorganismos más estudiados. La infección con EPEC es una de las causas más comunes de diarrea infantil en países en vías de desarrollo, como México. ${ }^{3-7}$ Esto último se debe en gran medida a que en el ámbito local se desconocen muchos aspectos relevantes acerca de la virulencia y el diagnóstico eficaz de EPEC, lo que repercute en el control adecuado de la enfermedad diarreica en los niños. En la presente revisión se refieren los avances en la patogénesis molecular de EPEC, la epidemiología y el diagnóstico de laboratorio. Asimismo, se delimita el riesgo potencial que representa EPEC para la población infantil y el mejor camino para su control.

\section{Escherrichia coli enteropatógen॰}

A mediados de la década de los cuarenta se identificaron en Inglaterra brotes de diarrea en niños de guarderías asociados a E. coli. Las bacterias se llamaron E. coli enteropatógenas (EPEC) para diferenciar a este tipo virulento de las bacterias de flora normal. ${ }^{8}$

Una de las principales características de la infección es la diarrea de tipo acuoso, que puede ocurrir en diversos grados de intensidad. Además, es común que los niños infectados presenten vómito y fiebre. El periodo de incubación varía de 3 a 24 horas después de que el individuo ingiere en condiciones experimentales un inóculo grande de bacterias ( $10^{9}$ a $\left.10^{10} \mathrm{UFC}\right)$; se cree que el inóculo que infecta de manera natural a los niños es mucho menor. ${ }^{3,5}$
Una vez que la bacteria alcanza la mucosa intestinal, comienza a desencadenarse un mecanismo de patogenicidad complejo, que tiene como resultado la producción de diarrea. Los niños menores de dos años son la población infantil con mayor susceptibilidad a la infección, y de ellos, la mayor prevalencia se ha observado en lactantes hasta de seis meses. ${ }^{2,5,9}$

De manera alarmante, las cifras de letalidad en países subdesarrollados son elevadas (20 a 50\%), lo que convierte a la infección por EPEC en una anomalía clínica de inmediata respuesta. Además, se ha notificado en algunos países latinoamericanos que la infección por EPEC supera a la provocada por Campylobacter spp. y rotavirus en la población infantil. 3,5

\section{Patogénesis molecular}

EPEC induce una alteración histopatológica en el intestino conocida como lesión A/E (adherencia y eliminación). La lesión se lleva a cabo mediante un mecanismo de virulencia complejo, que induce la degeneración de las microvellosidades y altera la morfología normal de la región apical del enterocito. ${ }^{10-12}$ Para fines prácticos, el modelo de patogénesis de EPEC se divide en tres fases: a) adherencia inicial, b) inyección de factores y transducción de señales, y c) contacto íntimo.

\section{Adherencia inicial}

La adherencia es un proceso fundamental en la patogénesis y de ella pueden distinguirse dos fases; la primera implica la adherencia inicial entre las mismas bacterias, mientras que la segunda supone la adherencia de las bacterias a la célula del huésped. Estos fenotipos están directamente relacionados con dos factores de virulencia importantes de EPEC: los pelos formadores de penachos (BFP, por sus siglas en inglés) y el flagelo (figura 1A). ${ }^{13-15}$

Los BFP son pelos o fimbrias de $7 \mathrm{~nm}$ de diámetro y 14 a $20 \mu \mathrm{m}$ de largo, cuya biogénesis requiere 14 genes codificados en el plásmido de virulencia denominado factor de adherencia de EPEC o EAF (figura 2A). En este 


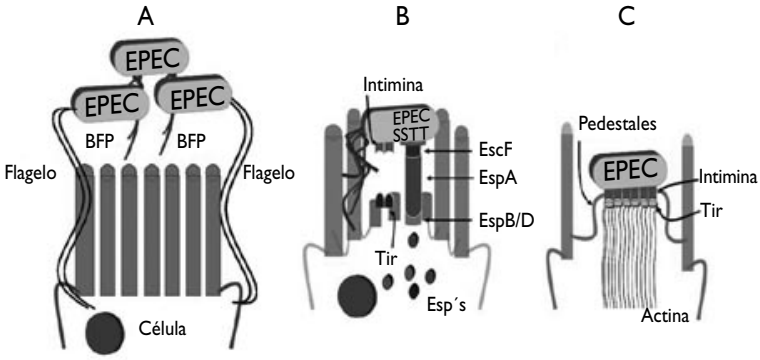

A) Los PFP permiten que las bacterias interactúen entre ellas para formar una microcolonia y el flagelo establece el contacto inicial de la microcolonia con la célula epitelial. B) Una vez adherida a la célula, EPEC inyecta factores de virulencia (Esp) mediante el SSTT-translocón, entre ellos Tir, que se inserta en la membrana de la célula y expone una región en el espacio extracelular. C) La intimina (una proteína de membrana externa) se une con firmeza a Tir y se induce el reacomodo del citoesqueleto, lo cual favorece la formación de los pedestales de actina y la desaparición de las microvellosidades absortivas; ello da lugar a la lesión $\mathrm{A} / \mathrm{E}$

\section{Figura I. Modelo esquemático de las etapas de la INFECCIÓN POR EPEC}

plásmido también están codificados los genes del operón per (regulador codificado en el plásmido) que regula la síntesis del BFP y las proteínas que secreta EPEC. 13,16,17 La expresión del BFP se induce in vitro en la fase de crecimiento logarítmico y lo regulan factores fisicoquímicos como la temperatura, el calcio y los iones amonio. Resulta interesante que todos éstos son factores que EPEC encuentra en el intestino delgado del huésped. ${ }^{16,18}$ Los BFP permiten que las bacterias se agrupen entre ellas y formen microcolonias (un fenotipo conocido como autoagregación) (figuras 1A y 3B); estos sucesos promueven la adherencia localizada típica de EPEC en cultivo de células in vitro (figura 3D) y el intestino delgado. 13,17,19

El contacto entre las bacterias y la célula del huésped se relaciona directamente con el flagelo de EPEC (figura 1A). Sin embargo, también se han referido otros factores como la adhesina intimina o los filamentos cortos de EspA..$^{14,20}$

\section{Inyección de factores y transducción de señales}

Una vez que la bacteria está adherida, inyecta a la célula una serie de proteínas mediante el sistema de secreción tipo III (SSTT) (figura 1B). La mayor parte de estas proteínas está codificada en el cromosoma de EPEC, dentro de una isla de patogenicidad de $35 \mathrm{~kb}$ conocida como el locus de la eliminación del enterocito o LEE (figura 2B). ${ }^{21-23}$

La isla de patogenicidad LEE está organizada en cinco operones policistrónicos ( $\mathrm{LEE}_{1}$ a $\left.\mathrm{LEE}_{5}\right)$; estos operones forman tres dominios de virulencia que codifican a los siguientes genes: a) los operones $\mathrm{LEE}_{1}, \mathrm{LEE}_{2}$ y LEE codifican los genes de las proteínas del SSTT, las cuales forman un complejo de aguja (CA); b) en el LEE 4 los genes de las proteínas que se secretan a través del SSTT las cuales se conocen de forma colectiva con el nombre de Esp (proteínas secretadas por EPEC); y c) en LEE 5 están codificadas la adhesina bacteriana intimina y su receptor, llamado Tir porque se transloca por la misma bacteria a través del SSTT hacia el interior de la célula. 10,24,25

Las proteínas del SSTT forman el CA; este complejo atraviesa la membrana interna, el espacio periplásmico y la membrana externa de la bacteria y permite la secreción de proteínas (figura 4). El CA es una compleja maquinaria macromolecular cuya estructura y función están conservadas dentro de un gran número de patógenos gramnegativos, como Yersinia, Shigella, Salmonella y EPEC. ${ }^{26}$ El SSTT de EPEC se ensambla de manera coordinada por al menos 19 proteínas; ${ }^{27}$ la plataforma del CA inicia con la localización de la proteína EscV en la membrana interna y EscC en la membrana externa (figura 4). A continuación se agregan otros componentes de membrana interna (EscR, EscS, EscT y EscU) que completan la plataforma del CA. La proteína EscN se agrega como el componente citosólico del SSTT; ésta funciona como una ATP-asa citoplásmica para proveer la energía necesaria al sistema. La lipoproteína EscJ

A) Plásmido EAF

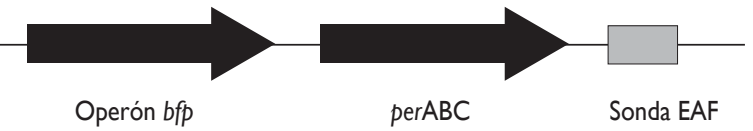

B) LEE

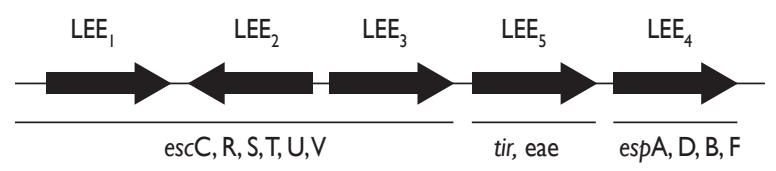

A) El plásmido EAF contiene todos los genes necesarios para la biogénesis de los pelos (BFP) y los genes del regulador perA, B y C. Una secuencia conservada dentro del plásmido EAF se ha utilizado como sonda para detectar cepas virulentas de EPEC tipo I (véase apartado Diagnóstico de EPEC). B) El LEE se divide en cinco operones policistrónicos que codifican en particular a tres dominios de virulencia. El primer dominio lo constituyen los operones $\mathrm{LEE}_{\text {, }}, \mathrm{LEE}_{2}$ y $\mathrm{LEE}_{3}$, los cuales codifican los genes de las proteínas del sistema de secreción tipo tres (SSTT). En el segundo dominio $\left(\mathrm{LEE}_{4}\right)$ están codificados los genes de las proteínas translocadoras y efectoras. El $\mathrm{LEE}_{5}$ (tercer dominio) contiene los genes que codifican a la adhesina intimina (eae) y el receptor de intimina Tir (tir)

Figura 2. Genes de Virulencia en el PLÁsmido EAF y EL LOCUS DE LA ELIMINACIÓN DEL ENTEROCITO (LEE)

salud pública de méxico / vol.49, no.5, septiembre-octubre de 2007 


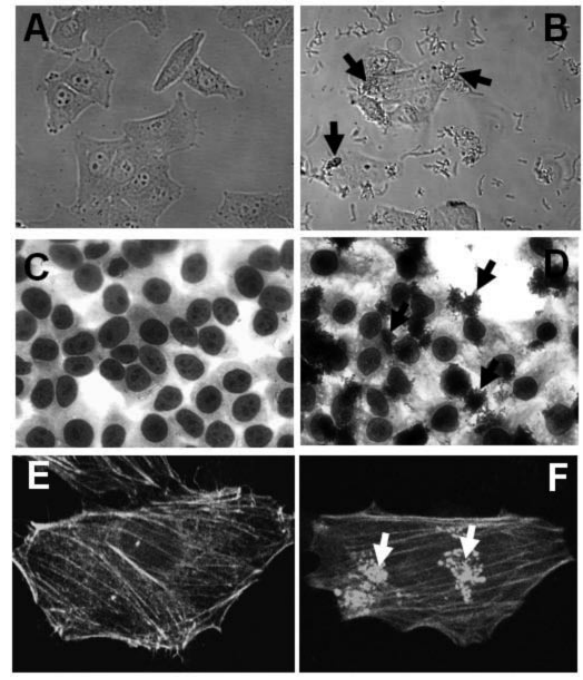

Células HEp-2 en cultivo in vitro observadas con microscopia de contraste de fases.A) Morfología característica del cultivo de células epiteliales HEp-2 no infectadas. B) Células HEp-2 infectadas durante dos horas con la cepa tipo EPEC (E2348/69); se observan las bacterias agrupadas entre ellas y la formación de la microcolonia (flechas negras), la cual se halla adherida a las células HEp-2. Ensayo de adherencia, células HEP-2 fijadas con metanol al $70 \%$ y teñidas con el colorante de Giemsa, microscopia de luz convencional). C) Morfología característica de cultivos de células HEp-2 no infectados. D) Adherencia localizada de EPEC a células HEp-2 después de tres horas de infección (flechas negras). Prueba de FAS [tinción fluorescente para actina], células fijadas con paraformaldehido al $2 \%$ y teñidas con faloidina rodaminada; microscopia de fluorescencia). E) Citoesqueleto de actina de células HEp-2 sin infectar (control) que muestra las fibras de estrés. F) Pedestales formados por la acumulación de la actina del citoesqueleto (flechas blancas) inducido por la infección con la cepa tipo EPEC durante tres horas

Figura 3. Detección de EpeC mediante el ensayo de ADHERENCIA Y LA PRUEBA DE FAS

conecta la plataforma en la membrana interna (EscR, EscS, EscT, EscU y EscV) con la proteína EscC en la membrana externa y forma un conducto cilíndrico que atraviesa el espacio periplásmico, a través del cual pasa la proteína EscF para establecerse finalmente como la punta del CA. Este complejo de aguja le permite a EPEC secretar proteínas hacia el medio extracelular. ${ }^{21,28-31}$

A través del CA pasan tres proteínas codificadas en el LEE conocidas como proteínas translocadoras. La primera de ellas, EspA, se ensambla directamente con EscF y se polimeriza en la punta o región distal del CA. La polimerización permite que la aguja molecular se extienda y forme un puente físico que posibilita el contacto entre la bacteria y la membrana de la célula (figura 4). ${ }^{32}$ Evidencias ultraestructurales han demostrado que EspA forma un conducto cilíndrico en cuyo interior pasan las proteínas EspB y EspD. Estas proteínas se hallan en la membrana de la célula eucariótica y completan el conducto llamado SSTT-translocón, que conecta y permite la comunicación molecular entre la bacteria y la célula y por el cual EPEC inyecta directamente a las proteínas efectoras de la virulencia. ${ }^{32-36}$

Las proteínas efectoras se han clasificado en proteínas codificadas en el LEE (EspF, EspG, EspH, EspZ, Map y Tir) y no codificadas en el LEE (Cif, EspG2, NleC, y NleD). ${ }^{37-44}$ EspF redistribuye proteínas importantes de las uniones estrechas intercelulares, con lo que se atenúa la resistencia transepitelial. ${ }^{40,45}$ EspG y EspG2 degradan la red de microtúbulos por debajo de donde se encuentra la bacteria adherida a la célula. ${ }^{37,42,46}$ Por su parte, EspH modula la estructura del citoesqueleto de actina, así como la formación de filopodios durante la lesión $\mathrm{A} / \mathrm{E}^{38}$ La proteína EspZ se acumula en zonas

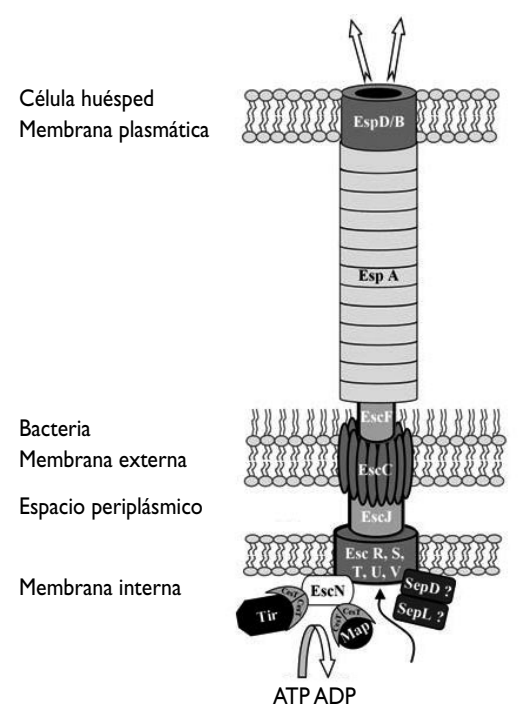

Las proteínas EscR, EscS, EscT, EscU y EscV del SSTT se insertan en la membrana interna de la bacteria para formar la plataforma del complejo de aguja (CA) y, de manera simultánea, la proteína $\mathrm{EscC}$ se coloca en la membrana externa. Mediante un mecanismo dependiente de Sec, la lipoproteína Esc] se sitúa en el espacio periplásmico y conecta a la plataforma en la membrana interna, así como a la EscC en la membrana externa. La proteína EscN está ligada de modo estrecho a la cara citosólica de la membrana interna; esta proteína es una ATP-asa que provee la energía necesaria para el transporte de proteínas; de esta manera pasa por el sistema la EscF, que se localiza en la punta del CA. Mediante este conducto pasa EspA hasta la punta, en donde interactúa con EscF y comienza a polimerizarse. La polimerización permite que el CA se alargue. La EspA forma un tubo cilíndrico que sirve para enviar a las proteínas EspB y EspD a la membrana de la célula en donde se colocan y terminan de formar el translocón-SSTT (complejo de aguja) por donde EPEC inyecta directamente proteínas de virulencia al citosol de la célula

Figura 4. Estructura hipotética del complejo de aguja DE EPEC 
donde crecen los pedestales de actina; empero, no se ha demostrado un papel específico dentro de la patogénesis de EPEC. ${ }^{39}$ Map se ubica con proteínas de la mitocondria, en donde altera el potencial de membrana y propicia la liberación del citocromo $\mathrm{C}$ e inducción de apoptosis. $^{47}$

Entre estos factores, la inyección de Tir en el citosol es un paso crucial durante la lesión A/E y la formación de los pedestales. El transporte de Tir a través del SSTT-translocón se lleva a cabo mediante una chaperona específica llamada CesT. ${ }^{48,49}$ Una vez en el citosol, un fragmento central de Tir (dominio hidrofóbico) se inserta dentro de la membrana plasmática de la célula, con lo que expone hacia el espacio extracelular un fragmento de 107 aminoácidos conocido como TIBA (área de unión a intimina), con el que se une a la proteína de membrana externa de EPEC llamada intimina (véase más adelante). ${ }^{48,50}$

\section{Contacto intimo y formación de pedestales}

La última etapa de la infección por EPEC se caracteriza por la unión estrecha entre la bacteria y la célula del huésped, así como la formación de los pedestales de actina (figura 1C). Tras la unión de Tir con intimina, aquél se fosforila en el residuo 474 por una proteína de la familia Src-cinasa conocida como c-Fyn. ${ }^{51} \mathrm{La}$ forma fosforilada de Tir recluta a la proteína adaptadora Nck, la cual atrae, interacciona y activa al final a otras proteínas reguladoras del citoesqueleto, como WASP (proteína del síndrome de Wiskott-Aldrich) y el complejo Arp2/3. Todas estas proteínas activadas atraen la polimerización de actina hacia la zona donde está Tir fosforilada, lo que inicia la reorganización del citoesqueleto. $^{52}$

Los pedestales se forman por debajo de donde la bacteria está adherida y se componen sobre todo de actina polimerizada y otras proteínas relacionadas con actina, como actinina $\alpha$, fimbrina, miosina, talina y ezrina. La reorganización del citoesqueleto altera la morfología y fisiología normal de la región apical de las células, lo que lleva al final a la pérdida de las microvellosidades intestinales y su función. ${ }^{11,53}$

\section{Diarrea indueida por EPEG}

A pesar de que se han estudiado con detalle cada uno de los episodios participantes en la formación de los pedestales, el mecanismo global de la diarrea en los niños infectados con EPEC no está claro. Se cree que el cambio de la configuración del enterocito reduce la absorción enzimática de nutrientes en el intestino. Sin embargo, la lesión A/E no se ha detectado en todas las biopsias de niños infectados, por lo que otros factores deben contribuir a la diarrea. ${ }^{5}$

Estudios realizados in vitro han demostrado que la infección reduce la resistencia eléctrica transepitelial de células MDCK (células de riñón canino Madin-Darbin) y Caco-2 (células de carcinoma de colon). Mutantes de EPEC con defectos en la adherencia íntima ( $\triangle e a e)$ o la formación de los pedestales no afectan la resistencia eléctrica normal de las células. La disminución de la resistencia eléctrica se ha vinculado con incrementos del $\mathrm{Ca}^{++}$intracelular y la redistribución de las uniones estrechas intercelulares. ${ }^{40,54,55}$ El potencial de membrana en reposo (PMR) también se altera cuando EPEC infecta a cultivos de células HeLa. Las células infectadas con la cepa de EPEC WT o la mutante en intimina ( $\triangle e a e)$ mostraron una reducción notable del PMR, mientras que en las células incubadas con la cepa mutante en el SSTT $(\Delta e s c \mathrm{~N})$ el PMR permaneció inalterado. ${ }^{56}$

La infección por EPEC a células Caco-2 o HeLa induce también incrementos electrofisiológicos de la corriente de cortocircuito (Isc) y la diferencia de potencial en cámaras de Ussing. El aumento de la Isc depende del SSTT y el translocón, ya que cepas mutantes en EspA, EspB, EspD o EscN no aumentan la Isc. . $^{57,58}$

Todos estos cambios en el gradiente electroquímico, que se exacerban por la disminución de la absorción intestinal y el incremento de la permeabilidad de la célula, son sin duda factores importantes dentro de la patogénesis de la diarrea secretora. ${ }^{9,24}$

En un esfuerzo por conocer de modo más pormenorizado el mecanismo molecular de la diarrea, en fecha reciente los autores demostraron que EspC (una proteína autotransportadora secretada por EPEC mediante el sistema de secreción tipo V, SSTV) induce la salida masiva de iones al espacio extracelular. La actividad enterotóxica se puso de manifiesto al incubar EspC purificada con tejido intestinal de rata montada en cámara de Ussing. ${ }^{59}$ Además de la actividad enterotóxica, la proteína EspC purificada es también una citotoxina. En experimentos realizados por Navarro-García y colaboradores se demostró que EspC induce daño al citoesqueleto de células HEp-2. ${ }^{60}$ El efecto citotoxico de EspC es muy parecido al que induce la toxina Pet (toxina codificada en un plásmido) de EAEC y otras toxinas autotransportadoras de enterobacterias. ${ }^{61-64}$

De manera interesante, el gen esp $\mathrm{C}$ sólo ha podido reconocerse en cepas de EPEC de tipo I, como se señala más adelante; estas cepas son las más virulentas. ${ }^{59}$ En fecha reciente también se ha encontrado que durante la infección de EPEC a cultivos de células epiteliales, la toxina EspC se envía directamente al citosol de la célula. A pesar de que el SSTV secreta EspC, el mecanismo de internalización parece tener la mediación del 
sistema de secreción tipo tres (SSTT). Los autores han localizado EspC en el interior de las células, aun antes de la formación completa de los pedestales de actina. La toxina inyectada por la bacteria (al igual que la toxina purificada) induce la contracción del citoesqueleto y la muerte de la célula epitelial, por lo que los autores han propuesto que EspC exacerba de manera notoria los síntomas de la diarrea en los niños. ${ }^{65}$

\section{Tipos virulentos de EPEG}

De manera distintiva, todas las cepas de EPEC contienen una isla de patogenicidad denominada LEE en el cromosoma bacteriano, mientras que sólo los aislamientos más virulentos codifican al plásmido EAF.66 Debido a estas características genotípicas hoy día se clasifica a EPEC en dos tipos virulentos: I y II. Las cepas que pertenecen al tipo I, además del LEE, codifican al plásmido de virulencia $\mathrm{EAF}$, en tanto que las de menor virulencia denominadas de tipo II no codifican Al plásmido EAF. ${ }^{5}$ Por otro lado, Trabulsi y colaboradores propusieron clasificar a las cepas de tipos I y II en cepas típicas y atípicas, respectivamente, con base en la presencia o ausencia del plásmido EAF y el fenotipo de adherencia. ${ }^{67}$ Las cepas típicas (de tipo I) presentan el patrón de adherencia localizada (LA, del inglés localized adherence) sobre cultivos de células epiteliales (figura 5A), mientras que las cepas atípicas (o de tipo II) poseen adherencia semejante a la localizada (LAL, por sus siglas en inglés) (figura 5B), adherencia difusa o, en algunos casos, adherencia agregativa. ${ }^{67}$

\section{Diagnóstice de EPEG}

Como cualquier E. coli, la bacteria se aísla de muestras de heces en medios selectivos y diferenciales para enterobacterias, como el agar de MacConkey o el agar de eosina y azul de metileno. Sin embargo, cuando se sospecha de un brote epidémico es necesario diferenciar los aislamientos de EPEC de las E. coli de flora normal, ya que son indistinguibles desde el punto de vista bioquímico y para ello se requieren pruebas adicionales distintas de las habituales realizadas en el laboratorio clínico. $5,68,69$

Para el diagnóstico de EPEC se utilizan las siguientes metodologías: a) serotipificación, b) ensayo de adherencia con células HEp-2, c) prueba de FAS (tinción fluorescente para actina) y d) técnicas de biología molecular que amplifican genes que codifican a proteínas de virulencia. ${ }^{3,5,69}$

La serotipificación fue el método que logró reconocer a tipos específicos de E. coli causantes de diarrea infantil en la década de 1940; de esa manera surgió el

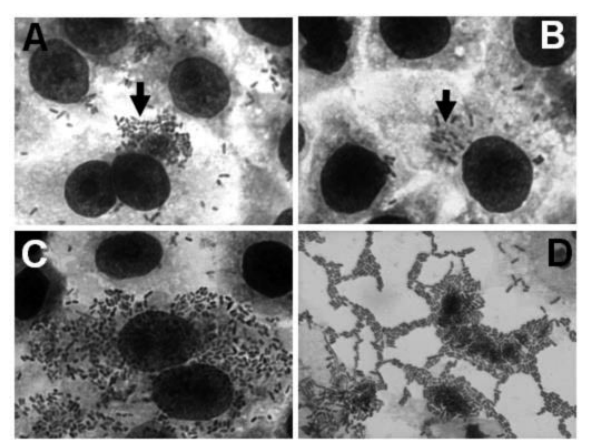

Ensayo de adherencia desarrollado por Cravioto y colaboradores. ${ }^{78}$ Células HEp-2 en cultivo in vitro infectadas durante tres horas con cepas diarreogénicas de $E$. coli, fijadas con metanol al $70 \%$, teñidas con el colorante de Giemsa y observadas bajo microscopia de luz convencional. A)Adherencia localizada (LA) de cepas de EPEC de tipo I, también llamadas cepas de EPEC típicas (flecha).B) Adherencia parecida a la localizada (LAL) de cepas de EPEC tipo II o atípicas; nótese que el tamaño de la microcolonia y el número de bacterias adheridas son menores respecto de las cepas con LA (flecha). C) Cepa de E. coli con adherencia difusa (EAEC); las bacterias se adhieren a toda la superficie de la célula en forma aleatoria. D) Cepa de E. coli con adherencia agregativa (EAEC); las bacterias se adhieren a la célula y el cristal en forma de ladrillos apilados o en palizada

Figura 5.Adherencia típica de cepas de E. coll diarreogéNICAS A CÉLULAS HEp-2

esquema de Kauffman, que todavía es una herramienta útil. ${ }^{5,70}$ En México, uno de los pioneros en el diagnóstico e investigación de enteropatógenos como E. coli fue Jorge Olarte, cuya prolífica investigación en el área data del decenio de $1950 .{ }^{71}$ Olarte y colaboradores desarrollaron técnicas para la recuperación óptima de enteropatógenos a partir de heces ${ }^{72}$ o sangre, como en Salmonella, ${ }^{73}$ y fue el primero en vincular serotipos específicos de E. coli con cuadros diarreicos en niños del Hospital Infantil de México Federico Gómez. Ellos aislaron una E. coli del serotipo O111:B4 (un serotipo típico de EPEC) de un caso mortal de diarrea; la llamaron Escherichia coli-gomez. ${ }^{70,74}$

En la actualidad, la serotipificación es todavía un instrumento valioso en el diagnóstico. En un trabajo que realizaron investigadores en Italia se detectaron mediante serotipificación cepas de EPEC aisladas de las heces de niños con diarrea. En dicho estudio, 75\% de los serotipos típicos vinculados con EPEC mostró uno o más factores de virulencia; ${ }^{75}$ cabe destacar que resultados similares a estos se han publicado en otras partes del mundo. ${ }^{76}$

Los autores recomiendan efectuar el análisis serológico de las cepas aisladas en México junto con otra 
metodología. Cravioto y colaboradores demostraron limitaciones del análisis serológico en cepas de EPEC aisladas en México de niños con diarrea. Las cepas de EPEC que ellos aislaron no pertenecían a serotipos comunes; pese a ello, se identificaron como EPEC mediante el ensayo de adhesión a células HEp-2, que a continuación se detalla. ${ }^{77}$

La prueba fenotípica de diagnóstico, considerada hoy el estándar de oro para la identificación de EPEC, es el ensayo de adherencia sobre células epiteliales HEp-2 que describieron de forma inicial Cravioto y colaboradores. Este método permite identificar EPEC dado que las bacterias se agrupan en cúmulos o microcolonias sobre las células epiteliales en cultivo (figura 3D, 5A); dicha disposición se conoce como adherencia localizada o fenotipo LA. ${ }^{78}$

Asimismo, con la citada técnica pueden también reconocerse E. coli enteroagregativa (EAEC); las bacterias de este tipo diarreogénico se agrupan y forman empalizadas que se adhieren a las células y al cristal (figura 5D); también puede identificarse E. coli adherente difusa (DAEC), reconocible porque las bacterias se adhieren a las células de forma aleatoria (figura 5C) $\cdot{ }^{79,80}$ Una variante de la técnica de Cravioto la propusieron en México Zepeda-López y González-Lugo, quienes prefijaron las células HEp-2 con metanol frío y añadieron las células bacterianas para estudiar los fenotipos de adhesión; los resultados obtenidos fueron idénticos a los descritos con la técnica tradicional. ${ }^{81}$

La prueba de FAS (tinción fluorescente para actina) es una técnica alternativa que se ha empleado con amplitud en estudios epidemiológicos y la investigación básica. ${ }^{82}$ Mediante este ensayo se observa la acumulación de la actina del citoesqueleto en la forma de puntos fluorescentes en la célula, en los que se encuentran los pedestales y las bacterias adheridas (figura 3F). La prueba de FAS se puede realizar de dos maneras: a) de modo directo en biopsias intestinales de niños con enfermedad diarreica con sospecha de infección por EPEC y b) en cultivos de células HEp-2, HeLa o Caco-2 infectadas con la cepa aislada de las heces del paciente. .,82,83 $^{-1}$

En la técnica se utiliza la faloidina, que es un compuesto que se une de manera constitutiva a la actina intracelular. Este compuesto se acopla a algún fluorocromo, casi siempre rodamina, de tal forma que mediante microscopia de fluorescencia es posible observar el citoesqueleto de actina de células epiteliales no infectadas con sus características fibras de estrés (figura 3E) y, además, puntos de acumulación de actina sobre las células infectadas por EPEC, algo que se denomina prueba de FAS positiva (FAS+) (figura 3F).

El ensayo de adherencia y la prueba de FAS son suficientes para relacionar una $E$. coli con el patotipo de
EPEC. Sin embargo, para tener la información completa acerca de la capacidad patogénica de la cepa aislada es preciso detectar genéticamente los factores de virulencia mediante técnicas de biología molecular. ${ }^{69,84}$

Los estudios moleculares se realizan sobre todo mediante la reacción en cadena de la polimerasa (PCR) y con sondas genéticas. Los blancos genéticos para identificar EPEC son una secuencia genética del plásmido EAF que se emplea como sonda o la amplificación por PCR de la subunidad estructural de los BFP ( $b f p \mathrm{~A})$ y el gen que codifica a la intimina (eae). ${ }^{69,84}$

En 1995, Gunzburg y colaboradores obtuvieron 100\% de especificidad en la detección de cepas de EPEC con adherencia localizada (LA+), tras amplificar el gen bfpA mediante PCR. De manera notable, la PCR para identificar EPEC se realiza en un tiempo menor de cinco horas y ello la hace una manera rápida y específica de diagnóstico. ${ }^{85}$ En México, la mayoría de los casos de diarrea que provoca EPEC no se identifica con regularidad; empero, el laboratorio de bacteriología molecular del Instituto de Diagnóstico y Referencia Epidemiológicos (InDRE) mantiene una vigilancia epidemiológica con herramientas diagnósticas moleculares como el colony blot y la PCR. ${ }^{69}$

Asimismo, López-Saucedo y colaboradores han desarrollado en México una reacción múltiple de PCR que permite detectar en una sola reacción cualquier tipo diarreogénico de $E$. coli con una alta sensibilidad, incluida EPEC. ${ }^{84,86}$ A diferencia de la reacción convencional (que sólo reconoce a una categoría diarreogénica), en la mezcla se incluyen varios pares de iniciadores para amplificar genes específicos de cada una de las categorías diarreogénicas de E. coli y que en el caso de EPEC se amplifica a los genes $b f p A$ y eae. La PCR múltiple es sensible y específica y se ha probado en cepas provenientes de muestras clínicas y alimentos con resultados satisfactorios. $^{84,86}$

En fecha reciente se ha desarrollado un ensayo que utiliza la tecnología de microarreglos de DNA, en la que se usan sondas con genes específicos de serotipos de E. coli como el O55, O111, O114, O128 y el O157. ${ }^{87}$ La misma tecnología de microrreglos se ha usado para extender el perfil de detección de antígenos somáticos de E. coli, así como a los antígenos flagelares. ${ }^{88}$

\section{Epidemiología}

Estudios epidemiológicos realizados en países en vías de desarrollo, incluidos Latinoamérica y México, han demostrado que ETEC y EPEC son dos de los principales patógenos aislados en los casos de diarrea infantil., 4, $89-92$

Dentro de la vigilancia epidemiológica que llevan a cabo las autoridades de salud en México, se ha co- 
municado que EPEC se presenta en forma endémica hasta en $6 \%$ de la población, ${ }^{93}$ una cifra muy parecida a la informada para países industrializados como Alemania y Australia, en los que se ha encontrado que 5.9 y $7.6 \%$, respectivamente, de niños sanos son portadores normales de cepas de EPEC (cuadro I). ${ }^{43}$

En lo que respecta a niños con diarrea, en México se ha detectado un alto porcentaje de pacientes infectados con EPEC. En un estudio que se condujo en Guadalajara, Jalisco, en 1987, se logró aislar cepas de EPEC en 17.5\% de los casos de niños menores de dos años con diarrea (cuadro I). En este estudio se identificó EPEC con mayor frecuencia que otros patógenos típicos, como Shigella, Giardia, Salmonella o rotavirus. ${ }^{94}$ Por otro lado, en 1991 Cravioto y colaboradores llevaron a cabo un estudio en niños con diarrea de una población rural del estado de Morelos. Ellos aislaron cepas de EPEC en 19\% de los casos de diarrea en niños de esa región. ${ }^{77}$

El grupo de investigación de los autores, en colaboración con el laboratorio de bacteriología médica del Hospital Infantil de México (SSA), ha logrado aislar E. coli con adherencia localizada (LA) en 7\% de 208 casos de niños con un cuadro diarreico grave (cepas del tipo I). Asimismo, 12\% de los casos se identificaron en cepas con adherencia parecida a la localizada (LAL) en este mismo grupo de pacientes (cepas del tipo II).

Cuadro I

Frecuencia de aislamiento de EPEC en niños con DIARREA Y SANOS EN DIVERSOS PAÍSES

\begin{tabular}{|c|c|c|c|c|}
\hline País (año) & 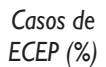 & $\begin{array}{c}\text { Controles } \\
(\%)\end{array}$ & $\begin{array}{c}\text { Método } \\
\text { diagnóstico }\end{array}$ & Referencia \\
\hline México (1987) & 17.5 & 7.4 & Adherencia & 94 \\
\hline Brasil (1989) & 23 & 2 & $\begin{array}{l}\text { Hibridación, } \\
\text { adherencia }\end{array}$ & 96 \\
\hline México (I99I) & 18 & 2 & $\begin{array}{l}\text { Adherencia, } \\
\text { hibridación y FAS }\end{array}$ & 77 \\
\hline China (199I) & 5 & NR & Hibridación & 97 \\
\hline Nigeria (2000) & 2.1 & 1.4 & $\begin{array}{l}\text { Hibridación, } \\
\text { adherencia }\end{array}$ & 100 \\
\hline Australia (2003) & NR & 7.6 & $\begin{array}{l}\text { PCR, hibridación, } \\
\text { adherencia y FAS }\end{array}$ & 43 \\
\hline Alemania (2003) & NR & 5.9 & $\begin{array}{l}\text { PCR, hibridación, } \\
\text { adherencia y FAS }\end{array}$ & 43 \\
\hline Chile (2003) & 5.3 & NR & PCR & 86 \\
\hline México (2004) & 19 & NR & Adherencia y FAS & 95 \\
\hline México (2005) & 25 & NR & PCR múltiple & 91 \\
\hline NR: no realizado & & & & \\
\hline
\end{tabular}

Estos resultados sugieren que las cepas EPEC (tipos I y II) inducen $17 \%$ de los casos graves de diarrea en niños que acuden al servicio de urgencias del Hospital Infantil de México (cuadro I). ${ }^{95}$

Datos similares comunicó el grupo de EstradaGarcía, que reconoció cepas de EPEC atípicas (cepas del tipo II) en $21 \%$ (sólo por debajo de ETEC, 27\%) de 62 casos de niños menores de cinco años internados por diarrea aguda en hospitales de la Ciudad de México y Villahermosa, Tabasco. ${ }^{91}$

Con estos datos epidemiológicos es posible advertir que EPEC es una bacteria causante de 17 a 19\% de los casos de diarrea infantil en diversas regiones del país, lo que indica que en México uno de cada cinco niños que enferman de diarrea puede estar infectado con este virotipo de E. coli.

En otras naciones en vías de desarrollo como Brasil y Chile, la epidemiología de EPEC es similar. ${ }^{86,96-98}$ Gomes y colaboradores (1989) encontraron que 23\% de cepas de E. coli con adherencia localizada (LA+) intervenía en grado significativo en casos de niños con diarrea, aun por encima de otros patógenos importantes como rotavirus o ETEC (cuadro I). ${ }^{96}$ Por su parte, Tornieporth y colaboradores notificaron que EPEC intervino sólo en $8 \%$ de los casos de diarrea aguda en niños del mismo país (cuadro I). ${ }^{98}$ Como hecho de interés, las EPEC atípicas son hoy las bacterias aisladas con más frecuencia de niños con diarrea en ese país, con una prevalencia elevada de $10.1^{92}$ a $16.4 \%{ }^{99}$

En la República de China se demostró que cepas de EPEC se aíslan en 5\% de los casos de diarrea de niños menores de tres años (cuadro I).${ }^{97}$ En Nigeria, Okeke y colaloradores realizaron un estudio en el que incluyeron a niños de áreas rurales; EPEC se aisló sólo en 2.1\% de los casos de diarrea. Sin embargo, no existió diferencia significativa respecto del aislamiento de EPEC en casos de niños con un cuadro diarreico y aquellos sujetos que no presentaban diarrea (cuadro I). ${ }^{100}$

\section{Discusión}

E. coli enteropatógena es una bacteria cuya epidemiología se ha estudiado poco en México, pese al riesgo que representa para niños menores de dos años. Este patógeno induce daño histológico en la mucosa del intestino delgado y lleva a los niños infectados en ocasiones a la muerte; en consecuencia, es importante contar con datos epidemiológicos fidedignos, así como una infraestructura institucional adecuada de diagnóstico para el control de esta infección intestinal. El mecanismo lesivo de EPEC es un proceso sumamente complejo, pero sin duda alguna muy eficiente para la bacteria. Una vez que alcanzan el intestino delgado, las 
bacterias se reproducen y comienzan a adherirse entre ellas hasta formar una microcolonia. Esta última entra en contacto con la célula del huésped mediante el flagelo y, de manera simultánea, sintetiza una aguja molecular por la cual le inyecta a la célula proteínas que alteran sus funciones normales. Por consiguiente, EPEC se adhiere con firmeza, remodela la superficie apical del enterocito y crea los pedestales de actina y compromete al final la fisiología normal del intestino, con diarrea resultante.

Los pedestales y la pérdida de las microvellosidades no son la única causa de la diarrea, pero sí factores importantes. Otro mecanismo de patogénesis que hoy se halla en estudio por el grupo de investigación de los autores es la secreción de EspC, una enterotoxina de la familia de las proteínas autotransportadoras.

En la mayor parte de los estudios epidemiológicos realizados en países en vías de desarrollo, así como en México, se ha observado que la infección por EPEC tiene una elevada tasa de morbilidad y mortalidad, lo que resalta la importancia de realizar un diagnóstico microbiológico certero y eficaz. Para identificar a las cepas provenientes de niños con diarrea, se efectúan metodologías diferentes de las habituales del laboratorio de microbiología. Dichas técnicas podrían estar al alcance de cualquier laboratorio clínico institucional por su sencillez, como la PCR múltiple. Casi todas las técnicas se llevan a cabo en laboratorios de investigación o laboratorios especializados de diagnóstico microbiológico, como en el caso del InDRE. El papel que tiene el InDRE en la actualidad en México es de vital importancia, con el fin de detectar y responder ante brotes epidémicos por EPEC y notificarlos a la Secretaría de Salud para su control. Por último, el diagnóstico oportuno y eficaz de la infección por EPEC es sin duda alguna un paso esencial para el buen pronóstico de los pacientes, sobre todo si se trata de niños menores de seis meses en los cuales se han visto elevadas tasas de mortalidad.

\section{Referencias}

I.Winfield MD, Groisman EA. Role of nonhost environments in the lifestyles of Salmonella and Escherichia coli.Appl Environ Microbiol 2003;69(7):3687-3694.

2. Kaper JB, Nataro JP, Mobley HL. Pathogenic Escherichia coli. Nat Rev Microbiol 2004;2(2): 123-140.

3. Cravioto A, Vasquez V. Escherichia coli: pathogenic mechanisms and enterohemorrhagic strains. Bol Med Hosp Infant Mex 1988;45(3): 196-197. 4. Clarke SC, Haigh RD, Freestone PP, Williams PH.Virulence of enteropathogenic Escherichia coli, a global pathogen. Clin Microbiol Rev 2003;16(3):365-378.

5. Nataro JP, Kaper JB. Diarrheagenic Escherichia coli. Clin Microbiol Rev I998; I I(I):| |42-20I.
6. Senerwa D, Olsvik O, Mutanda LN, Gathuma JM, Wachsmuth K. Colonization of neonates in a nursery ward with enteropathogenic Escherichia coli and correlation to the clinical histories of the children.J Clin Microbiol 1989;27(II):2539-2543.

7. Senerwa D, Olsvik O, Mutanda LN, et al. Enteropathogenic Escherichia coli serotype O I I :HNT isolated from preterm neonates in Nairobi, Kenya.J Clin Microbiol 1989;27(6): |307-I3 I .

8. Levine MM, Bergquist EJ, Nalin DR, et al. Escherichia coli strains that cause diarrhoea but do not produce heat-labile or heat-stable enterotoxins and are non-invasive. Lancet 1978; | (8074): | | | 9 - | 122. 9. Donnenberg MS, Kaper JB, Finlay BB. Interactions between enteropathogenic Escherichia coli and host epithelial cells. Trends Microbiol 1997;5(3):109-1 I4.

10. Celli J, Deng W, Finlay BB. Enteropathogenic Escherichia coli (EPEC) attachment to epithelial cells: exploiting the host cell cytoskeleton from the outside. Cell Microbiol 2000;2(I): I-9.

II. Finlay BB, Rosenshine I, Donnenberg MS, Kaper JB. Cytoskeletal composition of attaching and effacing lesions associated with enteropathogenic Escherichia coli adherence to HeLa cells. Infect Immun 1992;60(6):254I-2543.

12. Goosney DL, Gruenheid S, Finlay BB. Gut feelings: enteropathogenic E. coli (EPEC) interactions with the host. Annu Rev Cell Dev Biol 2000;16:173-189.

13. Giron JA, Ho AS, Schoolnik GK. An inducible bundle-forming pilus of enteropathogenic Escherichia coli. Science 1991;254(5032):710-713. 14. Nougayrede JP, Fernandes PJ, Donnenberg MS. Adhesion of enteropathogenic Escherichia coli to host cells. Cell Microbiol 2003:5(6):359-372.

15.Tórres AG, Zhou X, Kaper JB. Adherence of diarrheagenic Escherichia coli strains to epithelial cells. Infect Immun 2005;73(I):I8-29.

16. Ibarra JA, Villalba MI, Puente JL. Identification of the DNA binding sites of PerA, the transcriptional activator of the bfp and per operons in enteropathogenic Escherichia coli. J Bacteriol 2003; 185(9):2835-2847. 17. Donnenberg MS, Giron JA, Nataro JP, Kaper JB. A plasmid-encoded type IV fimbrial gene of enteropathogenic Escherichia coli associated with localized adherence. Mol Microbiol 1992;6(22):3427-3437.

18. Puente JL, Bieber D, Ramer SW, Murray W, Schoolnik GK. The bundleforming pili of enteropathogenic Escherichia coli: transcriptional regulation by environmental signals. Mol Microbiol 1996;20(I):87-100.

19. Bieber D, Ramer SW,Wu CY, et al. Type IV pili, transient bacterial aggregates, and virulence of enteropathogenic Escherichia coli. Science 1998;280(5372):2| |4-2| |8.

20. Giron JA, Torres AG, Freer E, Kaper JB. The flagella of enteropathogenic Escherichia coli mediate adherence to epithelial cells. Mol Microbiol 2002;44(2):361-379.

21. Garmendia J, Frankel G, Crepin VF. Enteropathogenic and enterohemorrhagic Escherichia coli infections: translocation, translocation, translocation. Infect Immun 2005;73(5):2573-2585.

22. Jarvis KG, Giron JA, Jerse AE, McDaniel TK, Donnenberg MS, Kaper JB. Enteropathogenic Escherichia coli contains a putative type III secretion system necessary for the export of proteins involved in attaching and effacing lesion formation. Proc Natl Acad Sci USA 1995;92 (17):7996-8000. 23. Kenny B, Finlay BB. Protein secretion by enteropathogenic Escherichia coli is essential for transducing signals to epithelial cells. Proc Natl Acad Sci USA 1995;92(I7):7991-7995.

24. DeVinney R, Knoechel DG, Finlay BB. Enteropathogenic Escherichia coli: cellular harassment. Curr Opin Microbiol 1999;2(I):83-88. 25. Elliott SJ,Wainwright LA, McDaniel TK, et al.The complete sequence of the locus of enterocyte effacement (LEE) from enteropathogenic Escherichia coli E2348/69. Mol Microbiol 1998;28(I): I-4.

26. Hueck CJ.Type III protein secretion systems in bacterial pathogens of animals and plants. Microbiol Mol Biol Rev 1998;62(2):379-433. 
27. Gruenheid S, Sekirov I, Thomas NA, et al. Identification and characterization of $\mathrm{NleA}$, a non-LEE-encoded type III translocated virulence factor of enterohaemorrhagic Escherichia coli OI57:H7. Mol Microbiol 2004;5I(5): I 233-I 249.

28. Crepin VF, Prasannan S, Shaw RK, et al. Structural and functional studies of the enteropathogenic Escherichia coli type III needle complex protein Esc]. Mol Microbiol 2005;55(6): I658-I670.

29. Yip CK, Kimbrough TG, Felise HB, et al. Structural characterization of the molecular platform for type III secretion system assembly. Nature 2005;435(7042):702-707

30. Gauthier A, Puente JL, Finlay BB. Secretin of the enteropathogenic Escherichia coli type III secretion system requires components of the type III apparatus for assembly and localization. Infect Immun 2003;7I(6):3310-3319.

3I. Hartland EL, Daniell SJ, Delahay RM, et al.The type III protein translocation system of enteropathogenic Escherichia coli involves EspAEspB protein interactions. Mol Microbiol 2000;35(6): | 483-I492. 32. Sekiya K, Ohishi M, Ogino T, Tamano K, Sasakawa C,Abe A. Supermolecular structure of the enteropathogenic Escherichia coli type III secretion system and its direct interaction with the EspA-sheath-like structure. Proc Natl Acad Sci USA 200 I;98(20): I I 638-I I 643. 33. Taylor KA, O'Connell CB, Luther PW, Donnenberg MS. The EspB protein of enteropathogenic Escherichia coli is targeted to the cytoplasm of infected HeLa cells. Infect Immun 1998;66( I I):550 I-5507.

34.Wolff C, Nisan I, Hanski E, Frankel G, Rosenshine I. Protein translocation into host epithelial cells by infecting enteropathogenic Escherichia coli. Mol Microbiol 1998;28(I):I43-I55.

35. Wachter C, Beinke C, Mattes M, Schmidt MA. Insertion of EspD into epithelial target cell membranes by infecting enteropathogenic Escherichia coli. Mol Microbiol 1999;3I(6): I695-I707.

36. Crepin VF, Shaw R, Abe CM, Knutton S, Frankel G. Polarity of enteropathogenic Escherichia coli EspA filament assembly and protein secretion. J Bacteriol 2005; I87(8):288I-2889.

37. Elliott SJ, Krejany EO, Mellies JL, Robins-Browne RM, Sasakawa C, Kaper JB. EspG, a novel type III system-secreted protein from enteropathogenic Escherichia coli with similarities to VirA of Shigella flexneri. Infect Immun 200I;69(6):4027-4033.

38. Tu X, Nisan I,Yona C, Hanski E, Rosenshine I. EspH, a new cytoskeleton-modulating effector of enterohaemorrhagic and enteropathogenic Escherichia coli. Mol Microbiol 2003;47(3):595-606. 39. Kanack KJ, Crawford JA, Tatsuno I, Karmali MA, Kaper JB. SepZ/EspZ is secreted and translocated into HeLa cells by the enteropathogenic Escherichia coli type III secretion system. Infect Immun 2005;73(7):43274337.

40. McNamara BP, Koutsouris A, O'Connell CB, Nougayrede JP, Donnenberg MS, Hecht G. Translocated EspF protein from enteropathogenic Escherichia coli disrupts host intestinal barrier function.J Clin Invest 200I; 107(5):62I-629.

4I. Kenny B, Jepson M.Targeting of an enteropathogenic Escherichia coli (EPEC) effector protein to host mitochondria. Cell Microbiol 2000;2(6):579-590.

42. Tomson FL, Viswanathan VK, Kanack KJ, et al. Enteropathogenic Escherichia coli EspG disrupts microtubules and in conjunction with Orf3 enhances perturbation of the tight junction barrier. Mol Microbiol 2005;56(2):447-464

43. Beutin L, Marches O, Bettelheim KA, et al. HEp-2 cell adherence, actin aggregation, and intimin types of attaching and effacing Escherichia coli strains isolated from healthy infants in Germany and Australia. Infect Immun 2003;7I(7):3995-4002.

44. Marches O,Wiles S, Dziva F, et al. Characterization of two non-locus of enterocyte effacement-encoded type III-translocated effectors, NleC and $\mathrm{NleD}$, in attaching and effacing pathogens. Infect Immun 2005;73(I2):84I I8417.

45. Viswanathan VK, Lukic S, Koutsouris A, Miao R, Muza MM, Hecht
G. Cytokeratin 18 interacts with the enteropathogenic Escherichia coli secreted protein $\mathrm{F}(\mathrm{EspF})$ and is redistributed after infection. Cell Microbiol 2004;6(10):987-997.

46. Matsuzawa T, Kuwae A,Abe A. Enteropathogenic Escherichia coli type III effectors EspG and EspG2 alter epithelial paracellular permeability. Infect Immun 2005;73(10):6283-6289.

47. Kenny B, Ellis S, Leard AD, Warawa J, Mellor H, Jepson MA. Co-ordinate regulation of distinct host cell signalling pathways by multifunctional enteropathogenic Escherichia coli effector molecules. Mol Microbiol 2002;44(4): 1095-I 107.

48. Kenny B, DeVinney R, Stein M, Reinscheid DJ, Frey EA, Finlay BB. Enteropathogenic $E$. coli (EPEC) transfers its receptor for intimate adherence into mammalian cells. Cell I997;9I(4):5I I-520.

49. Elliott SJ, Hutcheson SW, Dubois MS, et al. Identification of CesT, a chaperone for the type III secretion of Tir in enteropathogenic Escherichic coli. Mol Microbiol 1999;33(6): I I 76- I I89.

50. Kenny B. Phosphorylation of tyrosine 474 of the enteropathogenic Escherichia coli (EPEC) Tir receptor molecule is essential for actin nucleating activity and is preceded by additional host modifications. Mol Microbiol I999;3 |(4): |229-124I.

5I. Phillips N, Hayward RD, Koronakis V. Phosphorylation of the enteropathogenic $E$. coli receptor by the Src-family kinase c-Fyn triggers actin pedestal formation. Nat Cell Biol 2004;6(7):6I8-625. 52. Lommel S, Benesch S, Rohde M,Wehland J, Rottner K. Enterohaemorrhagic and enteropathogenic Escherichia coli use different mechanisms for actin pedestal formation that converge on N-WASP. Cell Microbiol 2004;6(3):243-254.

53. Goosney DL, DeVinney R, Pfuetzner RA, Frey EA, Strynadka NC, Finlay $B B$. Enteropathogenic E. coli translocated intimin receptor, Tir, interacts directly with alpha-actinin. Curr Biol 2000; I0(I2):735-738.

54. Canil C, Rosenshine I, Ruschkowski S, Donnenberg MS, Kaper JB, Finlay BB. Enteropathogenic Escherichia coli decreases the transepithelial electrical resistance of polarized epithelial monolayers. Infect Immun |993;6| (7):2755-2762.

55. Knutton S, Rosenshine I, Pallen MJ, et al.A novel EspA-associated surface organelle of enteropathogenic Escherichia coli involved in protein translocation into epithelial cells. Embo J 1998; I7(8):2166-2I76.

56. Stein M, Kenny B, Stein MA, Finlay BB. Characterization of EspC, a I IO kilodalton protein secreted by enteropathogenic Escherichia coli which is homologous to members of the immunoglobulin A protease-like family of secreted proteins. J Bacteriol 1996; I 78(22):6546-6554.

57. Collington GK, Booth IW, Donnenberg MS, Kaper JB, Knutton S. Enteropathogenic Escherichia coli virulence genes encoding secreted signalling proteins are essential for modulation of Caco-2 cell electrolyte transport. Infect Immun 1998;66(I2):6049-6053.

58. Collington GK, Booth IW, Knutton S. Rapid modulation of electrolyte transport in Caco-2 cell monolayers by enteropathogenic Escherichia coli (EPEC) infection. Gut 1998;42(2):200-207.

59. Mellies JL, Navarro-García F, Okeke I, Frederickson J, Nataro JP, Kaper JB. espC pathogenicity island of enteropathogenic Escherichia coli encodes an enterotoxin. Infect Immun 200 /;69(I):3I5-324.

60. Navarro-García F, Canizález-Román A, Sui BQ, Nataro JP,Azamar Y. The serine protease motif of EspC from enteropathogenic Escherichia coli produces epithelial damage by a mechanism different from that of Pet toxin from enteroaggregative E. coli. Infect Immun 2004;72(6):3609-362I. 61. Navarro-García F, Sears C, Eslava C, Cravioto A, Nataro JP. Cytoskeletal effects induced by pet, the serine protease enterotoxin of enteroaggregative Escherichia coli. Infect Immun 1999;67(5):2184-2192. 62. Canizalez-Roman A, Navarro-García F. Fodrin CaM-binding domain cleavage by Pet from enteroaggregative Escherichia coli leads to actin cytoskeletal disruption. Mol Microbiol 2003;48(4):947-958. 63. Henderson IR, Navarro-García F, Desvaux M, Fernández RC, 
Ala'Aldeen D. Type $V$ protein secretion pathway: the autotransporter story. Microbiol Mol Biol Rev 2004;68(4):692-744.

64. Dutta PR, Cappello R, Navarro-García F, Nataro JP. Functional comparison of serine protease autotransporters of enterobacteriaceae. Infect Immun 2002;70(I2):7|05-7| I3.

65.Vidal JE, Navarro-García F. Efficient translocation of EspC into epithelial cells depends on enteropathogenic Escherichia coli and host cell contact. Infect Immun 2006;74(4):2293-2303.

66. McDaniel TK, Jarvis KG, Donnenberg MS, Kaper JB.A genetic locus of enterocyte effacement conserved among diverse enterobacterial pathogens. Proc Natl Acad Sci USA 1995;92(5): I664-1668.

67. Trabulsi LR, Keller R, Tardelli Gomes TA. Typical and atypical enteropathogenic Escherichia coli. Emerg Infect Dis 2002;8(5):508-5I3. 68. Giono-Cerezo S, Rodríguez-Ángeles MG, Rodríguez-Cadena MJ, Valdespino-Gómez JL. Identification of enterotoxins and cytotoxins of Escherichia coli by Vero cell culture and solid-phase hybridization (colony blot). Rev Latinoam Microbiol 1994;36(4):23I-24I

69. Rodríguez-Ángeles G. Principal characteristics and diagnosis of the pathogenic groups of Escherichia coli. Salud Publica Mex 2002;44(5):464-475.

70. Olarte J,Varela G.A complete somatic antigen common to Salmonella adelaide, Escherichia coli-gomez, and Escherichia coli 0 I I I:B4.J Lab Clin Med 1952;40(2):252-254

71. Olarte J,Aldama A,Varela G. Epidemiology of infantile diarrhea and enteritis in the mexican republic and in the federal district. Prensa Med Mex 1952;17:168-176.

72. Olarte J. New method of obtaining samples for coproculture. Bol Med Hosp Infant Mex 1952;9:537-540.

73. De los Corvera MA, Olarte J, Ruiz Castañeda M.A new medium for the isolation of Brucella and Salmonella by blood culture. Bull World Health Organ 1956;14:797.

74.Varela G,Aguirre A, Carrillo J. Escherichia coli-gomez nueva especie aislada de un caso mortal de diarrea. Bol Med Hosp Infant Mex 1946;3:3. 75. Giammanco A, Maggio M, Giammanco G, et al. Characteristics of Escherichia coli strains belonging to enteropathogenic E. coli serogroups isolated in Italy from children with diarrhea.J Clin Microbiol 1996;34(3):689-94.

76. Campos LC, Franzolin MR, Trabulsi LR. Diarrheagenic Escherichia coli categories among the traditional enteropathogenic $E$. coli $O$ serogroups-a review. Mem Inst Oswaldo Cruz 2004;99(6):545-552.

77. Cravioto A, Tello A, Navarro A, et al.Association of Escherichia coli HEp-2 adherence patterns with type and duration of diarrhoea. Lancet 1991;337(8736):262-264

78. Cravioto A, Gross RJ, Scotland SM, Rowe B.An adhesive factor found in Escherichia coli belonging to the traditional infantile enteropathogenic serogroups. Microbiology 1979;6:3427-3437.

79. Scaletsky IC, Silva ML, Trabulsi LR. Distinctive patterns of adherence of enteropathogenic Escherichia coli to HeLa cells. Infect Immun 1984:45(2):534-536.

80. Scaletsky IC, Milani SR, Trabulsi LR, Travassos LR. Isolation and characterization of the localized adherence factor of enteropathogenic Escherichia coli. Infect Immun 1988;56(I I):2979-2983.

81. Zepeda-Lopez HM, Gonzalez-Lugo GM. Escherichia coli adherence to HEp-2 cells with prefixed cells.J Clin Microbiol 1995;33(5):1414-1417. 82. Knutton S, Baldwin T, Williams PH, McNeish AS. Actin accumulation at sites of bacterial adhesion to tissue culture cells: basis of a new diagnostic test for enteropathogenic and enterohemorrhagic Escherichia coli. Infect Immun 1989;57(4): I290-1298.

83. Knutton S, Lloyd DR, McNeish AS. Adhesion of enteropathogenic
Escherichia coli to human intestinal enterocytes and cultured human intestinal mucosa. Infect Immun 1987;55(I):69-77.

84. López-Saucedo C, Cerna JF,Villegas-Sepúlveda N, et al. Single multiplex polymerase chain reaction to detect diverse loci associated with diarrheagenic Escherichia coli. Emerg Infect Dis 2003;9(I):| 27-|3| . 85. Gunzburg ST, Tornieporth NG, Riley LW. Identification of enteropathogenic Escherichia coli by PCR-based detection of the bundleforming pilus gene.J Clin Microbiol 1995;33(5):1375-1377.

86.Vidal R,Vidal M, Lagos R, Levine M, Prado V. Multiplex PCR for diagnosis of enteric infections associated with diarrheagenic Escherichia coli. J Clin Microbiol 2004;42(4): 1787-1789.

87. LiY, Liu D, Cao B, et al. Development of a serotype-specific DNA microarray for identification of some Shigella and pathogenic Escherichic coli strains.J Clin Microbiol 2006;44(I 2):4376-4383.

88. Ballmer K, Korczak BM, Kuhnert P, Slickers P, Ehricht R, Hachler H. Fast DNA serotyping of Escherichia coli by use of an oligonucleotide microarray.J Clin Microbiol 2007;45(2):370-379.

89. Levine MM, Ferreccio C, Prado V, et al. Epidemiologic studies of Escherichia coli diarrheal infections in a low socioeconomic level periurban community in Santiago, Chile. Am J Epidemiol 1993; | 38(I0):849869.

90. Cravioto A, Reyes RE, Ortega R, Fernández G, Hernández R, López D. Prospective study of diarrhoeal disease in a cohort of rural Mexican children: incidence and isolated pathogens during the first two years of life. Epidemiol Infect 1988;10I(I):I23-134.

91. Estrada-García T, Cerna JF, Paheco-Gil L, et al. Drug-resistant diarrheogenic Escherichia coli, Mexico. Emerg Infect Dis 2005; I (8): 1306 1308.

92. Franzolin MR, Alves RC, Keller R, et al. Prevalence of diarrheagenic Escherichia coli in children with diarrhea in Salvador, Bahia, Brazil. Mem Inst Oswaldo Cruz 2005;100(4):359-363.

93. Flisser A, Velasco-Villa A, Martínez-Campos C, et al. Infectious diseases in Mexico.A survey from 1995-2000. Arch Med Res 2002;33(4):343-350. 94. Mathewson J], Oberhelman RA, Dupont HL, Javier de la Cabada F, Garibay EV. Enteroadherent Escherichia coli as a cause of diarrhea among children in Mexico. I Clin Microbiol 1987;25(I0):1917-1919.

95. Gutiérrez-Jiménez J,Vidal JE, Mejía-Albarrán ME, Resçendiz-Sánchez J, Pérez-Miravete A, Navarro-García F. Prevalencia de patotipos de Escherichia coli diarreogénica en niños del Hospital Infantil de Mexico. Memorias del 34o. Congreso Nacional de Microbiologia,Asociación Mexicana de Microbiología. 2004.

96. Gomes TA, Blake PA, Trabulsi LR. Prevalence of Escherichia coli strains with localized, diffuse, and aggregative adherence to HeLa cells in infants with diarrhea and matched controls.J Clin Microbiol 1989;27(2):266-269. 97. Kain KC, Barteluk RL, Kelly MT, et al. Etiology of childhood diarrhea in Beijing, China.J Clin Microbiol 199|;29(I):90-95.

98. Tornieporth NG, John J, Salgado K, et al. Differentiation of pathogenic Escherichia coli strains in Brazilian children by PCR.J Clin Microbiol 1995;33(5): |37|-|374.

99. Aranda KR, Fabbricotti SH, Fagundes-Neto U, Scaletsky IC. Single multiplex assay to identify simultaneously enteropathogenic, enteroaggregative, enterotoxigenic, enteroinvasive and Shiga toxinproducing Escherichia coli strains in Brazilian children. FEMS Microbiol Lett 2007;267(2): I 145-150.

100. Okeke IN, Lamikanra A, Steinruck H, Kaper JB. Characterization of Escherichia coli strains from cases of childhood diarrhea in provincial southwestern Nigeria.J Clin Microbiol 2000;38(I):7-I2. 